\title{
El Sentido De La Práctica Profesional En La Formación Del Docente De Educación Intercultural Bilingüe
}

\author{
The Meaning of Professional Practice in Intercultural Bilingual \\ Education Teacher Training
}

DOI: 10.54019/sesv3n1-015

Recebimento dos originais: 01/01/2021

Aceitação para publicação: 26/01/2021

\section{Manuel Abelardo Cárdenas Muñoz \\ Magister en Ciencias Sociales con mención en Políticas Educativas - FLACSO \\ Argentina \\ Licenciado en Educación - Pontificia Universidad Católica del Perú \\ E-mail: manuelcardenas1@gmail.com.}

\section{RESUMEN}

Pensar el lugar de la práctica preprofesional en la formación de docentes de educación intercultural bilingüe nos obliga como actores del proceso de ese encuentro entre sujetos sociales a explicitar los intereses de cada quién. Lugar que es territorio, espacio geográfico, pero también "sitio y momento" para vivenciar un proceso formativo decisivo en el proceso mayor de configurarnos como profesionales de la educación y ciudadanos. En tal sentido, el objetivo de la presente reflexión es profundizar en los efectos que las diversas ideas y prejuicios de los diferentes actores pueden ejercer en el accionar de la práctica profesional de los estudiantes, en especial de la carrera de educación. Pensando en ello, desde una mirada reflexiva de la experienciade formar docentes se propone una mirada que enfatiza en la necesidad de comprender la complejidad de procesos que moviliza la práctica preprofesional. Más aún, cuando motivados por las diferencias generacionales, culturales y otras se requiere la aplicación en el momento mismode la practica de una metodología que facilite la construcción de procesos de dialogo de saberes entre sujetos interculturales. Como docente de Universidades que formamos en Educación Intercultural Bilingüe podemos concluir a manera de aprendizajes de nuestra participación en esa modalidad que es altamente relevante: Desarrollar un accionar docente conjunto, entre colegas de un mismo ciclo de estudios y/o de una especialidad, nos permitirá lograr unificar esfuerzos, obteniendo resultados más adecuados y favorables para los propios estudiantes y nuestro propio quehacer andragógico. Podemos darle concreción a un modelo educativo emancipador cuando ponemos en acción metodologías que favorecen y promueven el aprendizaje activo, disponiéndonosa crear espacios en que las y los estudiantes tengan una viva presencia y participación en sus procesos de aprendizaje, para ello debemos asumirlos como sujetos de derechosy saberes. Sistematizar cada una de las experiencias formativas que den cuenta de la construcción de diálogos de saberes, para afirmar prácticas formativas interculturales, que respetan y empoderan diversidad de racionalidades en la formación docente. Construir una comunidad de aprendizaje con nuestros/as 
estudiantes y actores receptores que acompañe activamente los aprendizajes interculturales de cada uno de los/as estudiantes. Generar espacios para el empoderamiento de saberes de los pueblos originarios como otras formas de compresión de la realidad, motivando diálogos interculturales que enriquezcan la convivencia entre diversos. Pensar, planificar, ejecutar y evaluar la práctica profesional debe siempre conllevar unproceso de dialogo creativo, frecuente y permanente que permita explicitar, prestar atención y encausar en lo posible los intereses de todas y todos, las y los actores que intervienen en el proceso. Para ello se requieren voluntad, disposición y reconocimientodel otro como un sujeto integral.

\section{Palabras clave: Formación Docente, Interculturalidad, Práctica Profesional.}

\section{ABSTRACT}

Thinking about the place of pre-professional practice in the training of intercultural bilingual education teachers forces us, as actors in the process of this encounter between social subjects, to make explicit the interests of each one. Place is territory, geographic space, but also "place and moment" to experience a decisive formative process in the major process of shaping ourselves as education professionals and citizens. In this sense, the objective of the present reflection is to deepen in the effects that the diverse ideas and prejudices of the different actors can exert in the actions of the professional practice of the students, especially of the education career. Thinking about it, from a reflective view of the teacher training experience, we propose a view that emphasizes the need to understand the complexity of processes that mobilizes the pre-professional practice. Even more, when motivated by generational, cultural and other differences, the application of a methodology that facilitates the construction of processes of dialogue of knowledge between intercultural subjects is required at the very moment of practice. As teachers of Universities that train in Intercultural Bilingual Education, we can conclude as lessons learned from our participation in this modality that it is highly relevant: Developing a joint teaching action, among colleagues of the same cycle of studies and/or of a specialty, will allow us to unify efforts, obtaining more adequate and favorable results for the students and our own andragogical work. We can give concreteness to an emancipatory educational model when we put into action methodologies that favor and promote active learning, preparing ourselves to create spaces in which students have a lively presence and participation in their learning processes, for this we must assume them as subjects of rights and knowledge. Systematize each of the formative experiences that account for the construction of dialogues of knowledge, to affirm intercultural formative practices that respect and empower diversity of rationalities in teacher training. To build a learning community with our students and receiving actors that actively accompanies the intercultural learning of each one of the students. To generate spaces for the empowerment of the knowledge of native peoples as other forms of understanding reality, motivating intercultural dialogues that enrich coexistence among diverse people. Thinking, planning, executing and evaluating professional practice should always involve a process of creative, frequent and permanent dialogue that allows to make explicit, pay attention and channel as much as possible the interests of all the actors involved in the process. This requires willingness, disposition and recognition of the other as an integral subject. 
Key words: Teacher Education, Interculturality, Professional Practice.

\section{PENSANDO EN LA PRÁCTICA PREPROFESIONAL AL INTERIOR DE LOS PROCESOS DE FORMACIÓN}

El plan de estudios de diversas carreras profesionales como la educación, la medicina o laenfermería incluye la "puesta en acción" -en un espacio social determinado- de lo aprendido en las aulas institucionales. Ese contacto planificado de los estudiantes con la realidad es llamado comúnmente "práctica", preprofesional. Dicho nombre alude a que se le exigirá al "aprendiz" desarrollar desempeños intrínsecamente ligados a su futuro accionar como profesional.

Vale entonces plantear que la "práctica" es una acción educativa intencionada por la institución formadora, con objetivos claros y explícitos. En tal sentido, en el plano del diseño curricular los objetivos de la práctica deben de guardar coherencia con el ideario institucional como con el perfil ideal del futuro profesional y los lineamientos de política educativa del sector.Sobre estas líneas directrices se definen: (a) los desempeños de las competencias que los estudiantes deben de desarrollar; (b) se dosifica el logro de estas en un tiempo determinado, (c) se identificanlas estrategias de organización de la práctica; (d) la metodología para desarrollar dichas acciones; (e.) un campo o territorio determinado $y$, otros elementos que ayudan a configurar "la práctica" Sin embargo, este diseño ideal se ve enfrentado por las demandas y aspiraciones de la trama social en que se ubica. En el caso de una configuración social, diversa y cambiante como la peruana con "4'000,000 millones de indígenas según datos de INEI- UNICEF (UNESCO, 2013)" y “aproximadamente -a lo largo de todo el territorio peruano- 43 lenguas" (Alvarado, s.f.) vivas. Nos preguntamos entonces ¿Cómo este diseño responde a las necesidades y aspiraciones de los actores que participan en ella? En la formación de docentes conespecialidad en educación bilingüe intercultural en el Perú ¿Qué nuevas variables sociales exigen respuestas? ¿Cómo se teje en las realidades esta búsqueda de respuestas? 


\section{LA CONFIGURACIÓN DEL "CAMPO DE LA PRÁCTICA"}

Usualmente al inicio de cada semestre lectivo los docentes de cada institución formadoraal recibir la carga curricular a desarrollar revisan las finalidades, competencias y otros que lespermitan facilitar los cursos a su cargo. Muchas veces, esta acción es orientada, desde loslineamientos formales, cuando no acompañada por las autoridades institucionales encargadas devigilar el cumplimiento de la tarea formativa. Empieza entonces un dialogo cuando no un debateentre cada docente y su Coordinador o Directivo, del que no están exentos las/os otras/os docentes. Es más, es en ese momento cuando pueden surgir, al calor de diversas reuniones y momentos deintercambio de ideas, la posibilidad de acordar intencionalidades, actividades conjuntas, entre otras acciones posibles. Pero, también surgen desencuentros. $Y$ es que la explicitación de intereses, aspiraciones y deseos es un juego de poderes presentes y ocultos al interior de una tarea compleja. Algo similar sucede -con otras características- entre los estudiantes y los actores que recibirán a los futuros profesionales. Más allá de lo formal, operan en cada uno de estos actores, plurales y diversos, sus propios intereses y aspiraciones. Estas se presentan de diferentes maneras:una posibilidad es la expresión sincera de las mismas, otra es el ocultamiento tras palabrasgenerales y evasivas, cuando no a través de acciones del mismo calibre. Es decir, desde cada contexto y en cada actor van a existir un conjunto de expectativas e intereses explicitadas o no, tomadas en cuenta o no en las normas formales.

Sin embargo, y al calor de este debate, curiosamente, muchas veces se determina el espaciode la práctica preprofesional, llamado también campo, como si fuera un territorio físico. En el contexto antes planteado, a veces el campo es definido como un espacio lejano, distante de lo académico, cuando no folclórico, en el sentido en que en ese espacio vivieran seres observables, convertibles en sujetos de laboratorio, posibles de ser usados por la academia. En ambos casos pareciera que se aludiera a un objeto, olvidándose de la dimensión socio - cultural activa y presente, configurada por los propios actores de esta. Aún más, con Bourdieu podemos referir al campo de la práctica como "una red o configuración de relaciones objetivas entre posiciones" (Bourdieu, 2011). Es decir, un espacio simbólico de encuentro, configurado por los intereses, aspiraciones y deseos de 
los tres grandes actores, complejos y diversos que la desarrollan. Entonces, junto a los elementos formales, es en el encuentro vivo de los actores en que se van explicitando, cobrando fuerza y dando sentido - y contenido- a la práctica. Planteamos que, en ese juego dialéctico, lo formal hace las veces de un marco de referencia, pero son las acciones mismas de intercambio las que configuran su esencia.

¿Cómo se tejen esos procesos en una experiencia de "practica" preprofesional en que los futuros docentes -jóvenes de pueblos originarios- luego de haber cursado tres años en una institución de educación superior en Lima vuelven a sus lugares de origen, que curiosamente es el campo seleccionado? ¿Qué nuevos valores culturales y por lo tanto que nuevos sentidos otorgan a ese encuentro con sus familias, amigos, vecinos y docentes en que llegan a desarrollar un conjunto de desempeños profesionales en escuelas de educación bilingüe intercultural? ¿Cómo la práctica, espacio formativo e intencionado, se convierte en un espacio que permite un dialogo liberador, que permita explicitar junto con las aspiraciones, intereses y deseos se enuncien también los temores y las dudas?

\section{DE DÓNDE PROVIENES, ALLÍ VOLVERÁS}

Determinar el lugar físico, geográfico y humano en que va a operar la práctica es una decisión que, si bien compete a las autoridades de la institución educativa formadora, se conviertede alguna manera en otro tema de debate. La pregunta de fondo es: ¿Cumple este lugar con los criterios -vistos también como facilidades- para que los estudiantes logren las metas planteadas?

¿Existen las condiciones institucionales, culturales, sociales que permiten configurarlo como un escenario de construcción significativa del quehacer profesional, en nuestro caso del futuro docente? $Y$ es que no basta con que existan las condiciones físicas, ni tampoco las instituciones educativas, sino que además estas cumplan o presenten un conjunto de requisitos que las hagan espacios valiosos de aprendizaje. Es aquí entonces, cuando el actor "receptor" cobra una dimensiónmayor. Junto con la voluntad expresa de recibir en su ser delimitado por su quehacer, por su práctica a un conjunto de seres ajenos que vienen a observarlo, debe de haber logrado que este quehacer muestre un nivel 
de pertinencia cultural, innovación y búsqueda de transformación del aprendizaje de sus aprendices que haga de su labor una tarea interesante, admirable, posible de serpuesta como ejemplificadora de los desempeños esperados para un docente intercultural bilingüe. Exigencias nada fáciles de cumplir, pero que igual existiendo en un nivel considerable permiten afirmar que tanto el/la docente como la experiencia por él o ella motivada puede generar interesantes reflexiones y aprendizajes en los aprendices.

Entonces, al calor de estos requisitos se suman dos elementos importantes: uno, es el compartir ideales y expectativas sobre el aprendizaje de los aprendices; el otro, es el interés mutuode iniciar y mantener un dialogo de saberes -como mecanismo para lograr construir aprendizajes significativos- que beneficie a todos los actores intervinientes. Elementos de semejanza que permitirán un encuentro creativo y empático entre los actores. El segundo elemento plantea la posibilidad de que las condiciones se mantengan a lo largo del tiempo, desde el reconocerse comosujetos valiosos, poseedores de saberes que enriquecen la práctica de todos a lo largo del proceso. Este elemento permitirá que durante la práctica se puedan solucionar las tensiones, conflictos y dificultades que puedan gestarse.

Es en ese contexto en que la decisión sobre el "lugar de la práctica", en que aparece -casi como un imperativo- la posibilidad de jugando con las variables y las posibilidades que este no sea más que aquel del que emigraron los estudiantes. Finalmente, ese espacio entre otros reúne un conjunto de elementos conocidos para los actores intervinientes que podría garantizar un encuentro favorable y productivo para el aprendizaje entre los mismos. Y si no fuera así, que fuera un espaciosimilar, semejante, por sus características a las que podemos titular como capital cultural. La posibilidad del diálogo comprensivo, de la retroalimentación que sostiene e impulsa es crucial paraalcanzar el sentido de la práctica preprofesional. En tal sentido, el acortar la distancia entre el estudiante participante y la situación que va a encontrar - de alguna manera seleccionada por la institución formadora- es otro imperativo que tomar en cuenta. Es esa semejanza, esa supervivencia de elementos que faciliten un empate más comprensivo y dirigido hacia un mismo sentido será unagarantía suficiente para el logro de una práctica preprofesional productiva. 


\section{DIALOGO LIBERADOR}

Resueltas las condiciones antes planteadas, el proceso de la práctica exige, según el gradoy ciclo de los estudiantes mayores niveles de observación del quehacer del docente "modelo" o -según sea el caso- de la aplicación de técnicas, estrategias didácticas, cuando no de una sesión completa de aprendizaje con lo que ello conlleva. $Y$ es que cada una de estas, reúne un conjunto de habilidades y actitudes que se suman a la posibilidad de una reinserción exitosa en el "campo de la práctica". La identificación de la competencia sobre la que el aprendiz va a trabajar con los estudiantes del docente modelo, la técnica y/o metodología, los recursos, los términos a utilizar ytantos otros elementos, como la manera de dirigirse a los estudiantes, deben de ser conversados, acordados y consensuados con él o la docente receptor/a.

Este acto de "pasaje, iniciación" según sea el caso, puede haberse determinado previamente, incluso puede haber estado planificado en la secuencia didáctica del Curso de Práctica, pero en realidad responde a la voluntad del/la aprendizde iniciarse. Es él o ella quién atento a lo que viene viviendo dará el primer paso. Acto que le supone tanto aceptar su deseo, como encontrarse con su vocación, con sus ganas de aprender y deser, de atreverse incluso a conquistar ese espacio conocido llamado "aula o clase" desde otra posición: la del futuro docente. La tarea del docente acompañante como la del modelo será tanto motivar la puesta en acción como colaborar en la misma ayudando a fortalecer las ganas, procesarlo vivido, pensar en lo que se desea hacer hasta llegar a plasmarlo en un diseño instruccional perotambién en una experiencia formativa personal y colectiva.

En nuestro caso, como docentes acompañantes sugerimos la creación de un espacioalternativo, abierto, flexible, de encuentro y conversa, sin metas ni grandes propósitos más que lade acompañar las acciones realizadas. Y si bien ese espacio puede recibir a interesantes experiencias docentes que se desarrollan en la zona, estas serán significativas en la medida en queempaten con los intereses del grupo. 
A la raíz de la experiencia misma de la práctica entendida de esta manera reside el aprendizaje en el encuentro intercultural, en el reconocerse en el otro y en la otra, en el mirar a losojos reconociendo su saber. En los términos de Vicente Santuc en Ética y Política, "el hombre noes primero un individuo aislado frente a un mundo exterior. Ingresa siempre a un "mundo" ya allí" (Santuc, 1997) donde la acción humana en la historia se hace histórica en cuanto acción política. "Su querer es introducir un sentido en la historia" nos dice Santuc, agregamos nosotros en las personas, en los colectivos y colectividades. Entonces, la acción educativa dirigida a formar jóvenes futuros profesionales por un conjunto de adultos que comparten una visión y una intenciónparte de reconocer tanto el sentido de su acción como a los sujetos "jóvenes aprendices" como poseedores de saberes, expectativas y aspiraciones que los movilizan. Aquí, el corazón de la acciónformativa reside en el ser histórico de estos sujetos, que transforma y modifica a todos los demás.

\section{HACIENDO DEL DIALOGO DE SABERES UNA METODOLOGÍA PARA LA EDUCACIÓN DE JÓVENES Y ADULTOS}

En este punto es necesario plantear que la sección que continúa nació de un proceso de reflexión colectivo acunado en la acción cotidiana de educar educando a futuros docentesquechuas, shipibos y aimaras en la Facultad de Educación de la Universidad Peruana Cayetano Heredia, especialidad Educación Intercultural Bilingüe. Quien suscribe y transmite es solo un reciente actor en ese proceso entre estudiantes, docentes y directivos.

En la formación de docentes de Educación Intercultural Bilingüe, la pedagogía intercultural se constituye en el marco orientador para construir procesos de afirmación de la identidad de los estudiantes en formación. En ese proceso la identificación de formas diversas de discriminación, el análisis de sus causas y consecuencias y la construcción de mecanismos para afrontarla; el reconocimiento y valoración de diversas formas de entender la realidad y de distintas maneras deconstruir el conocimiento y de aprender; así como la toma de conciencia de la existencia de derechos individuales y colectivos desde la reflexión sobre el ejercicio de estos son procesosinherentes de gran valor. 
Esta configuración de la pedagogía intercultural no puede solo teorizarse, es decir, abordarse conceptualmente en la formación de los futuros docentes. Debe reconstruirse vivencialmente desde su propia historia de aprendizajes, permeada muchas veces por experienciaspoco estimulantes, con dolorosas situaciones de ruptura y vergüenza social, sobre todo cuando serefiere al espacio escolar. En tal sentido, como nos plantea:

"La metodología del diálogo, es decir, el cómo se lleva a cabo, implica una serie de bloques, varios de los cuales, a su vez, se descomponen. Los bloques serían los siguientes: Investigación previa, Interacción, Balance, Compromisos y Metacognición." (Mariño, 2016)

Sin embargo, en nuestro caminar pedagógico, el equipo de docentes de la modalidad de Educación Intercultural Bilingüe de la Facultad de Educación de la Universidad Peruana CayetanoHeredia hemos desarrollado una propuesta teórica - metodológica que utilizamos en nuestra práctica pedagógica. Rescatamos como esencia de esta la pedagogía de la liberación como pedagogía de praxis. La misma está fundada en el diálogo de saberes, en donde el conjunto de participantes en los procesos leyendo su vida y escribiéndola en su significado de claves y sentidosle permite reconocerse como un ser humano que sabe diferente a otros y que desde su saber puedenombrar el mundo, en su diferencia y construir sentidos y apuestas por hacer el mundo diferente. Citando a Marco Raúl Mejía podemos decir que esta empuja:

"Una toma de conciencia para ser sujeto con otros oprimidos y ser parte de la humanización del mundo, en donde no es posible tenerrepresentaciones de la opresión que no estén enmarcados en los supuestos básicos de la cultura y la sociedad en la que el oprimido está inmerso."

Lo cual coloca al orden del día lo político- pedagógico, en cuanto éste no se hace como tal por un discurso crítico que lo acompañe, sino por la manera como en todo su ejercicio construye relaciones sociales con intereses específicos. En ese sentido, los dispositivos que se utilizan en cada actividad educativa y pedagógica marcan el horizonte político del educador, es decir, él transforma la sociedad desde el cotidiano de su actuación como educador, y ahí el reconocimiento de cómo el poder que está en su actuar concretolo lleva a 
autocriticarse, en el sentido que lo político no es solo el horizonte emancipador de su discurso, sino también la manera como anticipa la nueva sociedad en su cotidiano pedagógico a través de los dispositivos que usa, "haciendo presente que no hay acción humana y educativa exenta de ser política."

Presentamos la secuencia metodológica resumida en el siguiente gráfico:

Gráfico 1. Propuesta metodología para desarrollar el "Dialogo de Saberes" Equipo de Docentes Facultad de Educación - Universidad Peruana Cayetano Heredia

5. Acciones de visibilización del aporte del saber originario y de otros saberes

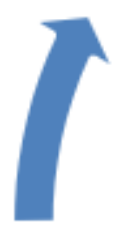

4. Conclusione sque orientan la acción
1. Reflexión de lavivencia

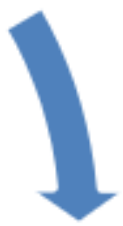

2. Sistematización y desarrollo de saberes sobre la vivencia
3. Compreensiónde De los saberes de las ciências

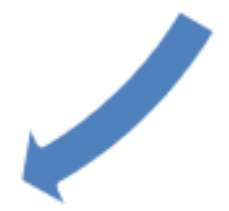

El análisis de la vivencia permite identificar en la experiencia de socialización cultural procesos educativos legítimos y valiosos para la conformación de su ser docente. "Es así como la experiencia individual se convierte en un punto de acción para lo social" (Figueroa, 2010). Por ejemplo, en el campo de la evaluación educativa, a modo de contraste con la experiencia escolar, las jóvenes identifican potencialidades en las prácticas evaluativas comunales para hacer más inclusiva y diversa la evaluación en la escuela.

La reflexión de la vivencia apertura un espacio para revaluar desde una dimensión crítica reflexiva la experiencia escolar y alimentar desde la 
revitalización de la sabiduría comunitaria formas alternativas de evaluación dentro de la pedagogía intercultural en este caso.

La reconstrucción de una vivencia puede cuestionar y poner en tensión los valores y prácticas comunitarias, como el de los roles asignados en la pervivencia familiar a varones y mujeres, los cuales se forman en él a partir de la exigencia, la dureza, la distancia afectiva; los mismos que se redimensionan en los espacios urbanos, incorporando la noción y el valor del derecho individual y la equidad en las relaciones ente individuos.

Entonces, la pregunta que surge es ¿Cómo se aborda la vivencia en el proceso de diálogo de saberes? En la experiencia desarrollada es siempre en el momento que apertura el abordaje de un tema o noción. Es allí cuando la vivencia pasada se recupera desde una situación de aprendizajeafectiva que pone al sujeto en dialogo con un par, otro joven varón o mujer que escucha y tambiéncon quién comparte su vivir, tejiendo lazos de cercanía y confianza pese a las diferencias culturales, de género y de edad.

Es preciso preguntarse si la vivencia individual es suficiente para recomponer los vínculoscon la cultura y hacer consciente la racionalidad que subyace a los saberes locales. Sin duda es insuficiente. Se requiere recuperar los significados profundos de estas sabidurías desde diferentesvoces, entretejiendo las experiencias y las reflexiones e identificando organizadores de información que permitan expresar en su real dimensión el aprendizaje. En otros espacios formativos universitarios más cercanos a las comunidades indígenas, estos significados se vuelvena dialogar con los ancianos, las mujeres, los especialistas en diferentes sabidurías, pero es responsabilidad también de los jóvenes organizar esta información. Es a este paso al que llamamos

"sistematización y desarrollo de saberes sobre la vivencia".

Sin embargo, no importa solo la dimensión expresiva en este momento, es clave además mirar los saberes en contexto, y dar cuenta de su condición de subordinación, de los desafíos queenfrenta limitaciones en su propia estructura por pérdida o desuso. Sin duda surgen desafíos quecomprometen a los jóvenes con la reproducción cultural situada y crítica. 
La experiencia muestra que los organizadores gráficos expresan mejor el universo de significados de la cosmovisión de los pueblos originarios, su belleza e integralidad para plasmar articuladamente las comprensiones del mundo, es reconocida desde el tiempo de la invasión y colonización y es un bien cultural que se trasciende de generación en generación.

Los y las jóvenes requieren además incorporar otras visiones sobre los hechos o conceptosque comprometen su formación y acercarse a aproximaciones teóricas construidas desde la cienciapositiva o interpretativa, menuda tarea que reviste una complejidad mayor dadas las deficiencias en su formación básica donde con frecuencia fueron compulsivamente obligados a apropiarse de la lectoescritura en otra lengua que no era su lengua materna. La lectura recreativa ayudó a hacer más amable este proceso, los organizadores de ideas expresados en mapas mentales donde se aprecian la relación entre conceptos fueron claves, porque precisamente se enganchan con su visión totalizadora del mundo, ayudaron también que compartieran sus comprensiones de los contenidos a través de canciones, teatralizaciones, poesías, murales. Comprendidos los contenidosdesde estas otras perspectivas recién fue posible tomar una postura personal frente a ellos, hacerlaentrar en diálogo con el saber originario y otorgarle validez para afrontar los problemas sociales yeducativos. Esto último permite a los profesionales "re-comunalizados" (Martínez, 2017) desarrollar múltiples destrezas. Entre ellas tener facilidad para contrastar las diferencias y similitudes entre la cosmovisión andina y la visión moderna (occidental) tejiendo nuevas y dinámicas simbiosis.

Desde la visión de los pueblos originarios un aprendizaje es efectivo solamente si es práctico, es decir ayuda a resolver un problema del contexto, si transforma el ser personal pero además el espacio colectivo y aporta a diseñar herramientas concretas de actuación. De ahí que elsaber sea entendido como el "conjunto de prácticas, señas, saberes, secretos, actitudes y valores que nacen como el resultado de una comunicación y relación constante entre estos 'entes' (PRATEC 2011: 18)

Una sesión de clase innovadora que aporta a la convivencia intercultural, un mural que dacuenta de la visión educativa de los pueblos originarios, una 
intervención educativa en escuelas urbanas para que comprendan y respeten las cosmovisiones andinas, una campaña en la universidad para interculturalizar las relaciones, los enfoques y las miradas de formación. De ahíque el saber sea entendido como el conjunto de prácticas, señas, saberes, secretos, actitudes y valores que nacen como el resultado de una comunicación y relación constante entre estos 'entes'(PRATEC 2011: 18)

La presencia pública a través de los productos de sus aprendizajes, poniendo en evidencia el valor de los saberes de los pueblos originarios y sus posibilidades de ser sistemáticos, científicos y de constituirse en referente formativo en los diferentes campos del conocimiento ha devuelto orgullo, identidad y afirmación a los estudiantes de educación intercultural bilingüe de estos pueblos. Además, ha revitalizado su construcción como ciudadanos en el sentido en que lo proponen Pinto y Osorio cuando plantean que:

La ciudadanía no es únicamente el atributo jurídico de la democracia, sino también es un proceso comunicacional, de generación de sentidos comunes, de desarrollo de capacidadesreflexiva, argumentativas, deliberativas y de promoción de recursos cívicos que acrecienten el capital social democrático y la participación ciudadana (Pinto y Osorio, 2014).

En tal sentido, es allí cuando se construyen en el sentido común los valores que configuran una ciudadanía comprometida, transformadora del dolor y la pobreza.

\section{SOBRE EL ACOMPAÑAMIENTO DE LOS SUJETOS DE LA PRÁCTICA}

Lograr que los niveles de dialogo alcanzados se mantengan durante la práctica misma es una tarea esencial a lo antes planteado. Para ello es necesario crear espacios de encuentro entre lospropios practicantes y el docente facilitador, entre los primeros y las organizaciones de base, las que sean y, por otro lado; reuniones entre los primeros con las autoridades y/o actores institucionales que han permitido nuestra presencia.

En esas acciones, con sus diversas modalidades se pone en acción el acompañamiento. Desde una visión de la práctica docente los educadores de Fe y Alegría de Colombia definen el acompañamiento como: 
Una acción o intervención continuada que consiste en caminar al lado de alguien para ofrecer aquello que somos, sabemos, podemos y poseemos, y así, facilitar la andadura delacompañado y que alcance su objetivo (Riveros, 2011).

Entonces, acompañar supone movilizar dentro de sí un conjunto de saberes, capacidades yactitudes que permitan una acción de ida y vuelta de creación conjunta de respuestas a problemas identificados por los actores del proceso. Más, el sentido final de las acciones de acompañamientoes facilitar que es "es unirse con alguien para ir a donde él va y al mismo tiempo" (Riveros, 2011).

Las acciones acompañamiento que se desarrollaron en la experiencia a la que nos referimos, se dieron en procesos mayores de formación docente. Este proceso, en la presente reflexión esntendida como:

Aprender a convivir, aprender a compartir, aprender a ser; sobre todo aprender empáticamente sobre cómo aprenden otros a ser ellos y ellas, a configurar la propia individualidad desde los entramados de la vida y el trabajo en equipo, en familia, en comunidad. (Martínez y González, 2010)

Comprendido de esta manera el acompañamiento en los procesos de formación fuesumamente importante desarrollar:

- Una Guía de observación y actividades a desarrollar durante el trabajo de campo que junto con pautear el trabajo a desarrollar por cada uno de los agentes participantes, en especial los practicantes y el docente facilitador, les permita expresar sus impresiones, percepciones y sentimientos. Vale recalcar que las actividades y contenidos de la Guíafueron consensuadas con los practicantes;

- Reuniones con docentes, autoridades y actores de la comunidad que cuenten con información y experiencias que permitan comprender tantos las características como ladinámica social y política de la localidad, ubicando a los actores -docente y facilitadores- en su accionar histórico.

- Encuentros de intercambio de sentires y pareceres sobre lo desarrollado en cada institución educativa por cada uno de los practicantes, dándoles el tiempo y facilitandolas condiciones para que exprese en libertad lo acontecido, así como también lo percibido; 
- Momentos de dialogo inter-personal dedicados a uno o dos practicantes participantes necesitados de expresar sus preocupaciones, deseos y aspiraciones.

- Acompañamiento in situ, en visita a las instituciones educativas del docente facilitador a los practicantes en las instituciones educativas en que desarrollaban su práctica.

Bajo estas acciones se planifico y desarrollo el acompañamiento a los estudiantes practicantes. Un eje central de los contenidos planteados durante el mismo fue la reflexión sobre el protagonismo de los niños y las niñas estudiantes en el quehacer docente. Una decisión inicial y altamente importante fue a evidenciar el diálogo de saberes como herramienta metodológica enla escuela. Para ello, los practicantes debían ayudar a los docentes titulares a tomar en cuenta los saberes previos de los niños y niñas sobre la situación de la comunidad, y la visión de los sabios o ancianos de la comunidad. Ellas/os valoraron entonces la relevancia de preguntas formular ciertas preguntas antes de iniciar la sesión de clase, en conversación con él o la docente.Por ejemplo: ¿Por qué sucede este problema en la comunidad? ¿Cómo afecta a los niños y las niñas este problema? ¿Cómo era antes nuestra comunidad? Estas preguntas se plantean con la idea de construir una visión común sobre el problema. "Entonces, los niños y las niñas pueden responder de diferentes maneras según la realidad en la que viven cada uno ellos y ellas. Por lo tanto, el docenteayuda a profundizar el tema con sus estudiantes y el sabio que ha sido invitado, para generar el diálogo del saber" (Cauper, 2018). Todo este proceso, tiene que ser desarrollado con mucha creatividad; formar grupos, realizar juegos lúdicos, representaciones y otros, para aprovechar los conocimientos locales del sabio y de los niños y las niñas.

Más, así como se rescató este aprendizaje hubo otros en relación al debate nacional sobre el currículo, la pertinencia de la educación intercultural bilingüe en zonas quechuas como en las que se realizó la práctica y como desarrollar está en contextos marcados por el empobrecimiento del campo, la marginación de los pueblos indígenas y la falta de sintonía entre las educativas nacionales y las demandas, así como las aspiraciones de las comunidades altoandinas. Estos 
pueblos indígenas organizados y movilizados "levantan la bandera de lo comunitario como defensade sus tradiciones culturales y de sus formas comunales de propiedad y poder" (Archila, 2011). Alrespecto Torres nos dice:

La emergencia de estas imágenes defensivas y alternativas de comunidad suele darse en contextos donde la convivencia humana se pone en peligro, ya sea para recuperar algo quese fue o que están en peligro por la irrupción capitalista del estado, o para pensarla como algo que puede construirse, como una promesa que hará realidad en el futuro (Torres, 2013).

Cabe destacar, que la respuesta educativa a construir en la práctica deberá estar dirigida "al rescate del diálogo pedagógico de saberes, para orientar al razonamiento crítico colectivo, a tomaren cuenta la posibilidad de reconstrucción mental de lo real como proceso intrínseco de la funciónlógica del pensar" (Pérez, Sánchez y Norys, 2009). Es entonces cuando para fundamentar las acciones a desarrollar y ya ejecutadas se hace necesario recuperar el pensamiento vivo y palpitantede Paulo Freire cuando nos dice: "sino amo al mundo, sino amo la vida, no me es posible el dialogo" (Freire, 1983). Por ello, se hace imprescindible aprender y reaprender la disposición, lossaberes y capacidades que nos permitan dialogar con el otro, con el próximo. O cuando el mismoFreire plantea en "Cartas a quien pretende enseñar":

Es preciso que ese amor sea en realidad un "amor armado", un amor luchador de quien se afirma en el derecho o en el deber de tener el derecho de luchar, de denunciar, de anunciar.Es ésta la forma de amar indispensable para el educador progresista y que es preciso que todos nosotros aprendamos y vivamos (Freire, 1998).

Reflexionando con los estudiantes participantes en la práctica decíamos que tomar encuenta estas ideas nos impulsaban a un accionar nuevo, creador de vida visible en acciones pedagógicas renovadas en que el aprender a ser docente además de requerir de una renovación integral de acciones nos construía como sujetos de derechos, formadores de otros. 


\section{CONCLUSIONES}

Las conclusiones que podemos plantear nos permiten desarrollar un balance de nuestra participación en el proceso de práctica profesional nos permite afirmar que:

Si es posible desarrollar un accionar docente conjunto, entre colegas del mismo ciclo de una especialidad, logrando unificar esfuerzos y obteniendo resultados más adecuados y favorables para los propios estudiantes y nuestro propio quehacer docente.

- Podemos darle concreción al modelo educativo de la Facultad cuando ponemos en acción metodologías que favorecen y promueven el aprendizaje activo, disponiéndonosa crear espacios en que las y los estudiantes tengan una viva presencia y participación en sus procesos de aprendizaje, para ello debemos asumirlos como sujetos de derechosy saberes.

- En el campo de la Educación Intercultural Bilingüe (EIB), debemos generar y sistematizar cada una de las experiencias formativas en el nivel superior que den cuentade la construcción de diálogos de saberes, para afirmar prácticas formativas interculturales, que respetan y empoderan diversidad de racionalidades en la formacióndocente.

- Los docentes que afrontan el desafío de formar docentes EIB, requieren construir una comunidad de aprendizaje que acompañe activamente los aprendizajes interculturales de cada uno de los estudiantes.

- Las Universidades que desarrollan programa de formación docente $\mathrm{EIB}$, deben generarespacios para el empoderamiento de saberes de los pueblos originarios como otras formas de compresión de la realidad, motivando diálogos interculturales que enriquezcan la convivencia entre diversos.

- Pensar, planificar, ejecutar y evaluar la práctica profesional debe siempre conllevar unproceso de dialogo creativo, frecuente y permanente que permita explicitar, prestar atención y encausar en lo posible los intereses de todas y todos, las y los actores que intervienen en el proceso. Para ello se requieren voluntad, disposición y reconocimientodel otro como un sujeto integral.

Por tanto, dar sentido a la práctica profesional exige en los diferentes actores desarrollar una serie de habilidades y actitudes. Ellas van desde la 
voluntad de aprendizaje y enseñanza mutua, hasta tener sensibilidad para compenetrarse con la sabiduría campesina andina y facilidad para generar y planificar acciones concretas. En suma, deben ser capaces de construir proyectos de desarrollo que combinen conocimientos ancestrales andinos con los occidentales y/o técnicos. 


\section{REFERÊNCIAS}

Alvarado campos, lizbeth. Las lenguas en el perú: un panorama de las lenguas indígenas. Pontificia universidad católica del perú \& universidad nacional federico villarreal. En: hápax no 4, 49-68.

Archila, mauricio (2011). "economía y cultura para el buen vivir en el movimiento indígenacaucano", en: controversia, \# 197, bogotá.

Bourdieu, pierre; wacquant, loïc (1992) respuestas. Por una antropología reflexiva, grijalbo, méxico

Cauper, saúl y kelly vásquez. Diálogo de saberes en la educación intercultural bilingüe 28febrero 2018. Disponible en

http://www.upch.edu.pe/faedu/index.php/noticias/1533-dialogo-

De-saberes-en-la-educacion-intercultural-bilinguee

Figueroa alcántara, hugo. Movimientos sociales y diversidad cultural: estrategias de rescate y difusión en el universo editorial y de la información. En: morales campos, estela (coordinadora). Rescate y difusión de la diversidad cultural en el mundo global. México: unam, centro universitario de investigaciones bibliotecológicas, 2010. Xi, 187 p. (cuadernos de investigación; 13.)

Freire, p. Pedagogía del oprimido. México: siglo xxi editores, 1983.

Freire, p. Cartas a quien pretende enseñar. México: siglo xxi editores, 1998.

Héctor a. Martínez d., sandra gonzález pons. Acompañamiento pedagógico y profesionalización. En: ciencia y sociedad, vol. Xxxv, número 3, 2010, 521-541 Kusch, r. El pensamiento indígena y popular en américa. Buenos aires: hachétte, 1977.

Mariño s. Germán. El diálogo en la educación popular: entre idealizaciones y prácticas concretas. En: pedagogías y metodologías de la educación popular "se hace camino al andar" ceaal - colectivo colombia editores y compiladores: Iola cendales, marco raúl mejía y jairo muñoz m. Bogotá. 2016.

Martinez, maria fernanda. Comunicación intercultural y rescate de saberes y prácticas ancestrales: el acompañamiento de la asociación bartolomé aripaylla en la comunidad

Campesina de quispillaccta (ayacucho). En: canalé 07. Comunicación +desarrollo. Lima. 2017

Mejia, marco raúl. Diálogo-confrontación de saberes y negociación cultural. En: pedagogías y metodologías de la educación popular "se hace camino al andar" ceaal - colectivo colombiaeditores y compiladores: lola cendales, marco raúl mejía y jairo muñoz m. Bogotá. 2016. 
Pinto, r.; osorio, j. (col.). Pedagogía crítica para una educación pública y transformadora en américa latina. Lima: derrama magisterial, 2014. (colección cooperación con la formación docente en américa latina, v. li).

Pérez luna, enrique, sánchez carreño, josé, alfonzo, norys, saber pedagógico y diálogo de saberes en la formación docente. Laurus. 2009, 15 (enero-abril) Programa andino de tecnologias campesinas (pratec). Afirmación cultural

Andina. Lima: pratec. 1993

Riveros, elizabeth. El acompañamiento y la educación popular. Bogotá. 2011.

Santuc, v. S., j. Vicente. ¿qué nos pasa? Ética y política hoy. Cedep. Lima, 1997. $170 \mathrm{pp}$.

Torres carrillo, alfonso. El retorno a la comunidad: problemas, debates y desafíos de vivirjuntos. Cinde - bogotá. 2013.

Unesco - ministerio de cultura del perú. Indicadores unesco de cultura para el desarrollo. Resumen analítico. Lima. 2013.

Villa, h. Sistematizar para saber, devenir y resistir. Sistematizando la sistematización de haceresde resistencia con vos y con voz en la corporación combos. Tesis de grado cinde. 2015. 